\title{
UTILIZAÇÃO DAS METAS AICHI NA AVALIAÇÃO \\ DO PLANO DIRETOR MUNICIPAL DE SÃO CARLOS-SP
}

USE OF AICHI TARGETS IN EVALUATION OF SÃO CARLOS-SP MASTER PLAN

\section{Diego Peruchi Trevisan', Luiz Eduardo Moschini²}

\begin{abstract}
RESUMO
O crescimento das cidades intensificou de modo significativo os impactos negativos sobre os ambientes naturais. Nesse contexto, os Planos Diretores possuem um papel essencial como instrumento de política urbana auxiliando no planejamento e gestão municipal. O objetivo deste trabalho é avaliar o Plano Diretor de 2005 e o Plano Diretor Estratégico do município de São Carlos tomando como critérios as metas Aichi de biodiversidade, propondo notas do Grau A ao Grau G, conforme a escala proposta por Fischer (2010). Verificou-se que, com relação à conservação da biodiversidade, os planos apresentam lacunas, uma vez ambos possuem ausência de informações detalhadas sobre as atividades relacionadas à conservação dos ecossistemas. Recomenda-se a revisão do plano em processo de revisão para que ocorra a inserção dos elementos deficientes das Metas de Aichi, para que assim ocorra a promoção da conservação da biodiversidade e um desenvolvimento sustentável no município de São Carlos.
\end{abstract}

Palavras-chave: Plano diretor. Avaliação estratégica. Qualidade ambiental. Conservação da biodiversidade.

\begin{abstract}
The growth of cities has intensified significantly negative impacts on environments. In this context, the Master Plans have an essential role as urban policy instrument assisting the municipal planning and management. The aim of this work is to assess the Master Plan of 2005 and the Strategic Master Plan of São Carlos taking as criteria the Aichi biodiversity targets, proposing Grade A Notes to Grade G, according the scale proposed by Fischer. It has been verified that, in relation to the conservation of biodiversity, the plans have gaps, since both haven't detailed information on the activities related to the conservation of ecosystems. It is recommended to revise the plan under review so that the deficient elements of the Aichi Goals can be inserted, so as to promote the conservation of biodiversity and sustainable development in the municipality of São Carlos.
\end{abstract}

Keywords: Master plan. Strategic assessment. Environmental Quality. Biodiversity Conservation.

\section{INTRODUÇÃO}

O processo de transformação da paisagem como sendo o incremento da urbanização, fruto de um êxodo rural, está associado principalmente ao desenvolvimento da civilização e da tecnologia que proporcionam maiores concentrações demográficas nos centros urbanizados. Expandindo-se

\footnotetext{
1 Doutorando em Ciências Ambientais pela Universidade Federal de São Carlos (São Carlos/Brasil). E-mail: diego.peruchi@gmail.com.

${ }^{2}$ Doutor em Ecologia e Recursos Naturais pela Universidade Federal de São Carlos (São Carlos/Brasil). Professor na Universidade Federal de São Carlos (São Carlos/Brasil). E-mail: lemoschini@ufscar.br.
} 
principalmente na segunda metade do século XVIII com a Revolução Industrial (MENDONÇA, 2016, p.13).

As cidades desenvolvem-se como o território suporte para as atividades por constituírem espaços de concentração e condições necessárias as diversas atividades de produção. Entretanto a rápida expansão e desenvolvimento resultaram em um crescimento desordenado das cidades, as quais estão despreparadas para atender às necessidades básicas dos migrantes (DAVIES et al., 2011, p.1127).

Este crescimento potencializou a intensificação das pressões antrópicas sobre o ambiente natural em decorrência do crescimento econômico e populacional. Observa-se um crescente processo de substituição das paisagens naturais por outros usos da terra, convertendo extensas e contínuas áreas com cobertura florestal em fragmentos florestais, afetando a disponibilidade e a qualidade dos recursos naturais (SOUZA, 2004, p16).

Os impactos antropogênicos tendem a simplificar os ecossistemas naturais, reduzindo a resistência intrínseca à mudança e rompendo seus limiares de resiliência em mais de um lugar ao mesmo tempo. Por ocorrerem de maneira desigual nos ecossistemas, essas alterações podem exacerbar as desigualdades no acesso aos serviços ambientais, contribuindo ainda mais para a indigência (TREVISAN, 2015, p.33).

Tornou-se necessário o fortalecimento dos espaços de participação por meio da mobilização da população e de suas instâncias de representação, o qual deve ser uma premissa da administração municipal. Tal participação é necessária para a formulação, execução e acompanhamento de planos, programas e projetos de desenvolvimento urbano, com o intuito de formular o planejamento das cidades com a finalidade de promover a justa distribuição espacial da população e das atividades econômicas (CNM, 2006, p.22).

No âmbito brasileiro, o plano diretor é uma ferramenta essencial para o planejamento do crescimento municipal. Previsto pela Constituição Brasileira de 1988 e pela Lei Federal 10.257 de 2001 (Estatuto da Cidade). Este deve ser base da política de desenvolvimento e expansão urbana, tendo como objetivo o melhoramento da qualidade de vida da sociedade além da ordenação do desenvolvimento e das funções sociais, estabelecendo princípios, normais e diretrizes a serem seguidas (BRAGA, 1993, p.70).

Entretanto, uma das dificuldades identificadas na proposição de políticas, planos, programas e projetos tem sido a relação destes com a interface ambiental, buscando prever, orientar e adequar os possíveis impactos que as diversas atividades possam causar.

A sustentabilidade econômica, sob o âmbito do desenvolvimento sustentável é um conjunto de medidas políticas que visam a incorporação de preocupações e conceitos ambientais e sociais. Assim, presume-se a incorporação da gestão mais eficiente dos recursos naturais, de forma a garantir uma exploração sustentável acrescentando aos elementos naturais um valor econômico (DAVIES et al., 2011, p.1130).

Com estes princípios, a Convenção da Diversidade Ecológica foi estabelecida durante a ECO-92: Conferência das Nações Unidas sobre Meio Ambiente e Desenvolvimento (CNUMAD), realizada no Rio de Janeiro em junho de 1992, sendo hoje o principal fórum mundial para questões relacionadas a temática ambiental (MMA, 2016, p.01).

A convenção foi estruturada sobre três bases principais: a conservação da diversidade biológica, o uso sustentável da biodiversidade e a repartição justa e equitativa dos benefícios provenientes da utilização dos recursos genéticos, se referindo à biodiversidade em três níveis: ecossistemas, espécies e recursos genéticos (MMA, 2016, p.01). 
As questões ambientais, quando tratadas junto às demandas sociais e às pressões econômicas, podem ser suprimidas em função de diferentes interesses. A realização de uma Avaliação Ambiental Estratégica durante a revisão do Plano Diretor Municipal poderia garantir que as questões ambientais sejam discutidas, esclarecidas e acordadas entre os atores envolvidos, que estariam mais aptos a discutir e assimilar as consequências ecológicas de suas ações no desenvolvimento urbano (NETO; SOUZA, 2010).

Pode-se considerar que os processos culturais transformadores das paisagens constituem a manifestação integrada dos elementos naturais e culturais, ocasionando mudanças físicas ou culturais na mesma e que o ambiente natural proporciona benefícios para a sociedade de diversos modos ao preservarem a estrutura e função dos ecossistemas (BALMFORD et al., 2002, p.951).

Estes benefícios devem motivar a conservação da natureza diante das pressões econômicas crescentes sobre o ambiente natural, embora a avaliação socioeconômica dos mesmos seja um processo difícil (SANTOS et al., 2001, p.173) e não incorporado na atividade econômica convencional baseada, principalmente na análise de mercado.

Diante destas considerações, o objetivo deste trabalho foi avaliar o Plano Diretor (PD) Municipal do município de São Carlos-SP vigente desde 2005 e o Plano Diretor Estratégico (PDE) em processo de elaboração em 2016 - 17 de acordo com as metas Aichi de biodiversidade.

\section{MATERIAL E MÉTODOS}

\section{1 ÁREA DE ESTUDO}

O município de São Carlos, localiza-se na região Administrativa Central do Estado de São Paulo (IGC, 2016), entre as coordenadas $22^{\circ} 09^{\prime} 39^{\prime \prime}$ e $21^{\circ} 35^{\prime} 50^{\prime \prime}$ de latitude sul e $48^{\circ} 05^{\prime} 27^{\prime \prime}$ e $47^{\circ} 43^{\prime} 09^{\prime \prime}$ de longitude oeste, com $1.140 \mathrm{~km}^{2}$ (Figura 1) (IBGE, 2016, p.01).

Figura 1 - Localização geográfica do município brasileiro de São Carlos (SP)

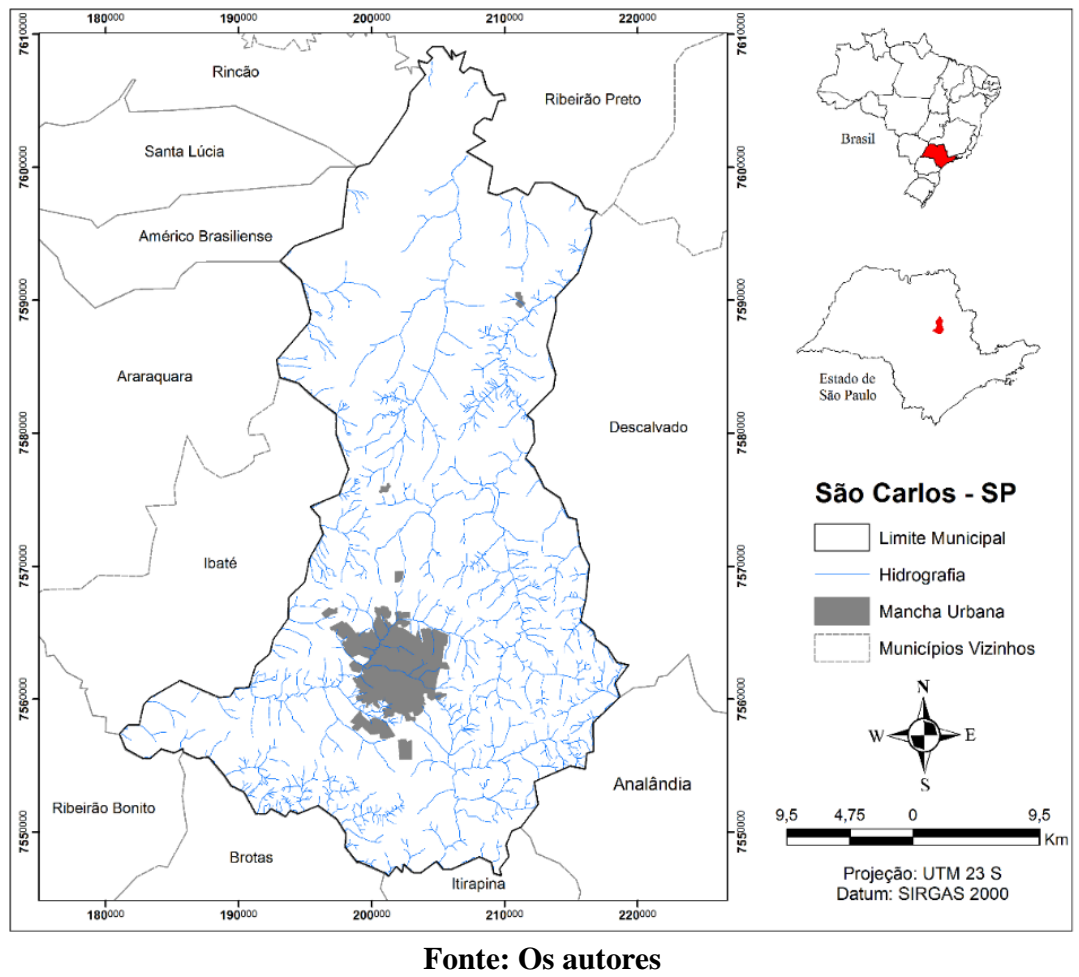


O município possui população de 230.890 habitantes (densidade demográfica de 203 habitantes por $\mathrm{km}^{2}$ ), com grau de urbanização de $96,00 \%$ e taxa de crescimento anual da população em 1,02 (SEADE, 2016, p.01).

O clima caracteriza-se como tropical de altitude com inverno seco, relevo de planalto e bioma de Cerrado. A temperatura média aproxima-se de $21,12^{\circ} \mathrm{C}$ e média mensal pluviométrica de $118,56 \mathrm{~mm}$ num total de 1.422,8mm anuais (CEPAGRI, 2016, p.01).

\subsubsection{Plano Diretor de São Carlos}

Com a ampliação da ocupação dos espaços naturais e sua transformação em espaços urbanos, o desenvolvimento de ferramentas de ordenamento do território e de desenvolvimento urbano tornou-se essencial. Nesse contexto, uma das modalidades de planejamento urbano que vem se desenvolvendo durante as últimas décadas no Brasil é expressa através dos planos diretores (VILLAÇA, 2010, p.01).

A própria Constituição Federal garante a elaboração do plano diretor a municípios que possuam mais de vinte mil habitantes. Segundo o artigo $182^{\circ}$ (BRASIL, 1988, p.01):

Art. $182^{\circ}$ - A política de desenvolvimento urbano, executada pelo Poder Público municipal, conforme diretrizes gerais fixadas em lei, tem por objetivo ordenar o pleno desenvolvimento das funções sociais da cidade e garantir o bem-estar de seus habitantes.

$\S 1^{\circ} \mathrm{O}$ plano diretor, aprovado pela Câmara Municipal, obrigatório para cidades com mais de vinte mil habitantes, é o instrumento básico da política de desenvolvimento e de expansão urbana.

Como um instrumento de política urbana do município, este possui um papel primordial em sua elaboração e execução. O plano diretor municipal e o planejamento estratégico municipal constituemse como instrumentos de imensa importância nas mãos do poder público municipal os quais auxiliam no processo de planejamento e gestão de questões urbanísticas. Esses instrumentos devem obedecer a hierarquia constituída pela Constituição Federal - Lei de Responsabilidade Fiscal, relativa à administração de recursos e pelo Estatuto de Cidade (REZENDE et al., 2007, p.258)

Não há como não abordar a questão da urbanização dissociada das questões ambientais, uma vez que qualquer tipo de intervenção gerada sobre o meio, independente se esse processo ocorre de modo mais ou menos agressivo, gera efeitos sobre o ecossistema presente. Segundo Braga (2001, p.95, p.98)

[...] o avanço da urbanização sobre o meio natural, de maneira desordenada, tem causado a degradação progressiva de áreas de mananciais, com a implantação de loteamentos irregulares e a instalação de usos e índices de ocupação incompatíveis com a capacidade de suporte do meio. A ordenação do processo do uso e ocupação do solo urbano, atividade de competência municipal, deve ser questão prioritária numa política de gestão ambiental.

O Plano Diretor de São Carlos, está em vigor desde 2005, por meio da Lei $n^{\circ}$ 13.691/2005, prevendo revisão a cada cinco anos, no intuito de analisar e avaliar o uso e ocupação do solo, as tendências à expansão urbana, definir as zonas de restrição à ocupação e a demarcação das diretrizes viárias a fim de ordenar o desenvolvimento urbano do município (SÃO CARLOS, 2016, p.01).

O Plano Diretor Estratégico (PDE) do município de São Carlos, ainda em processo de aprovação, vem em detrimento da revisão do plano diretor anterior. O PDE contempla e define:

I. Os seus princípios fundamentais;

II. A função social da cidade e da propriedade;

III. As funções do ordenamento territorial;

IV. As diretrizes da política habitacional;

V. O macrozoneamento e o zoneamento municipal; 
VI. Os limites do perímetro urbano;

VII. As áreas de especial interesse;

VIII. A hierarquização das vias urbanas e as diretrizes viárias e da mobilidade urbana;

IX. As diretrizes para o parcelamento do solo e para a implantação de loteamentos e condomínios;

$\mathrm{X}$. Os instrumentos da política urbana;

XI. Sistema municipal de gestão e planejamento do desenvolvimento urbano.

\subsection{MÉTODOS UTILIZADOS}

\subsubsection{Metas Aichi}

A Conferência das Partes (COP) é o órgão decisório no âmbito da Convenção sobre Diversidade Biológica (CDB). Trata-se de reunião das delegações oficiais dos 188 membros da Convenção sobre Diversidade Biológica, representantes dos principais órgãos internacionais, organizações acadêmicas, organizações não-governamentais e empresariais, lideranças, entre outros. Durante a Conferência das Partes em 2010 em Nagoya (Japão), foram realizadas revisões no Plano Estratégico para a Biodiversidade, sendo estabelecidas as Metas de Aichi que correspondem a metas relacionadas a conservação da biodiversidade, abrangendo o período de 2011 a 2020 (CBD, 2016, p.01) divididas em cinco objetivos estratégicos (Tabela 1).

Tabela 1 - Objetivos estratégicos estabelecidos na Conferência em Nagoya

\begin{tabular}{l|l}
\hline Objetivo & Descrição \\
\hline A & $\begin{array}{l}\text { Tratar das causas fundamentais de perda de biodiversidade fazendo com que preocupações com } \\
\text { biodiversidade permeiem governo e sociedade }\end{array}$ \\
\hline B & Reduzir as pressões diretas sobre biodiversidade e promover o uso sustentável sociedade \\
\hline C & Melhorar a situação de biodiversidade protegendo ecossistemas, espécies e diversidade genética \\
\hline D & $\begin{array}{l}\text { Aumentar os benefícios de biodiversidade e serviços ecossistêmicos para todos ecossistemas, espécies } \\
\text { e diversidade genética }\end{array}$ \\
\hline E & $\begin{array}{l}\text { Aprimorar, ampliar a implementação por meio do planejamento participativo, gestão de conhecimento } \\
\text { e capacitação. }\end{array}$ \\
\hline
\end{tabular}

Fonte: CDB (2016), SÃO PAULO (2013)

Tais objetivos desdobram-se em 20 componentes (Tabela 2) para a promoção da conservação da biodiversidade em nível mundial (SCDB, 2014, p.120).

Tabela 2 - Objetivos estratégicos e suas respectivas metas

\begin{tabular}{|c|c|}
\hline & Metas de Aichi \\
\hline \multirow{4}{*}{ 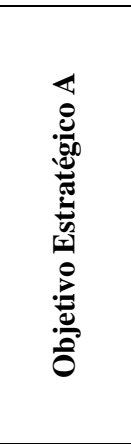 } & $\begin{array}{l}\text { 01. Em } 2020 \text {, no mais tardar, as pessoas devem estar cientes dos valores da biodiversidade e do que podem } \\
\text { fazer para conservá-la }\end{array}$ \\
\hline & $\begin{array}{l}\text { 02. Em 2020, no mais tardar, os valores de biodiversidade devem estar integrados a estratégias de } \\
\text { desenvolvimento e de redução da pobreza, a processos de planejamento nacionais e locais e estar incorporados } \\
\text { à contabilidade nacional, de maneira adequada, e a sistemas de documentação e comunicação }\end{array}$ \\
\hline & $\begin{array}{l}\text { 03. Em 2020, no mais tardar, incentivos nocivos à biodiversidade devem estar eliminados ou reformulados } \\
\text { para minimizar ou evitar impactos negativos e incentivos positivos para a conservação e o uso sustentável da } \\
\text { biodiversidade devem estar desenvolvidos e aplicados, em consistência e harmonia com a Convenção e outras } \\
\text { obrigações nacionais relevantes, levando em conta as condições socioeconômicas nacionais }\end{array}$ \\
\hline & $\begin{array}{l}\text { 04. Em 2020, no mais tardar, governos, negócios e tomadores de decisão, em todos os níveis, devem seguir } \\
\text { etapas para alcançar ou ter planos implementados para consumo e produção sustentável e devem manter os } \\
\text { impactos do uso de recursos naturais dentro dos limites ecológicos seguros. }\end{array}$ \\
\hline \multirow{2}{*}{ ص } & $\begin{array}{l}\text { 05.Em 2020, a taxa de perda de todos os habitats naturais, incluindo florestas, deve estar reduzida a mais que } \\
\text { a metade e, se possível, levada a zero, e a degradação e a fragmentação devem ser significativamente reduzidas. }\end{array}$ \\
\hline & $\begin{array}{l}\text { 06. Em 2020, todos os estoques de peixes e invertebrados e plantas aquáticas devem estar gerenciados e } \\
\text { aproveitados de maneira sustentável, legal e com base na adoção de abordagem ecossistêmica, de maneira que } \\
\text { a pesca em excesso seja evitada, planos e medidas de recuperação sejam implementados para todas as espécies } \\
\text { esgotadas, a pesca não tenha impactos adversos significativos em espécies ameaçadas e ecossistemas }\end{array}$ \\
\hline
\end{tabular}




\begin{tabular}{|c|c|}
\hline & $\begin{array}{l}\text { vulneráveis e o impacto da pesca em estoques, espécies e ecossistemas estejam dentro dos limites ecológicos } \\
\text { seguros. }\end{array}$ \\
\hline & $\begin{array}{l}\text { 07. Em 2020, áreas com agricultura, aquicultura e silvicultura devem ser gerenciadas de maneira sustentável, } \\
\text { assegurando a conservação da biodiversidade. }\end{array}$ \\
\hline & $\begin{array}{l}\text { 08. Em 2020, a poluição, incluindo aquela decorrente do excesso de nutrientes, deve estar em níveis não } \\
\text { prejudiciais à biodiversidade e à função do ecossistema }\end{array}$ \\
\hline & $\begin{array}{l}\text { 09. Em 2020, espécies exóticas invasoras e rotas de introdução devem estar identificadas e priorizadas; } \\
\text { espécies prioritárias devem estar controladas ou erradicadas e devem ser adotadas medidas para gerenciar as } \\
\text { rotas, prevenindo a introdução e o estabelecimento de espécies exóticas invasoras. }\end{array}$ \\
\hline & $\begin{array}{l}\text { 10. Em } 2015 \text {, as múltiplas pressões antropogênicas sobre recifes de corais, e outros ecossistemas vulneráveis } \\
\text { impactados por mudança climática ou acidificação do oceano, devem estar minimizadas, de modo a manter } \\
\text { sua integridade e funcionamento. }\end{array}$ \\
\hline \multirow{3}{*}{ 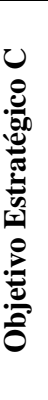 } & $\begin{array}{l}\text { 11. Em } 2020 \text {, pelo menos } 17 \% \text { das zonas terrestres e de águas continentais, e } 10 \% \text { das zonas costeiras e } \\
\text { marinhas, especialmente áreas de importância particular para biodiversidade e serviços ecossistemicos, devem } \\
\text { estar conservadas por meio de gerenciamento eficiente e equitativo, ecologicamente representadas, com } \\
\text { sistemas bem conectados de áreas protegidas e outras medidas eficientes de conservação baseadas em área, e } \\
\text { integradas em mais amplas paisagens terrestres e marinhas. }\end{array}$ \\
\hline & $\begin{array}{l}\text { 12. Em 2020, a extinção de espécies em extinção conhecidas deve estar prevenida e sua situação de } \\
\text { conservação, particularmente para aquelas de maior declínio, melhorada e sustentada. }\end{array}$ \\
\hline & $\begin{array}{l}\text { 13. Em } 2020 \text {, a diversidade genética de plantas cultivadas e animais domésticos e de seus parentes selvagens, } \\
\text { incluindo outras espécies de importância social, econômica e cultural, deve estar mantida, e devem ser } \\
\text { desenvolvidas e implementadas estratégias para minimizar a erosão genética e proteger sua diversidade } \\
\text { genética. }\end{array}$ \\
\hline \multirow{3}{*}{ 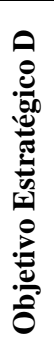 } & $\begin{array}{l}\text { 14. Em 2020, ecossistemas que fornecem serviços essenciais, incluindo serviços relacionados à água, e } \\
\text { contribuem para a saúde, sustento e bem-estar, devem estar restaurados e protegidos, levando em conta as } \\
\text { necessidades da mulher, dos indígenas e de comunidades locais, e dos pobres e vulneráveis. }\end{array}$ \\
\hline & $\begin{array}{l}\text { 15. Em 2020, a resiliência dos ecossistemas e a contribuição da biodiversidade para os estoques de carbono } \\
\text { devem estar ampliadas, por meio de conservação e restauração, incluindo restauração de, pelo menos, } 15 \% \text { de } \\
\text { ecossistemas degradados, desta forma, contribuindo para mitigação da mudança climática e para adaptação e } \\
\text { para o combate à desertificação. }\end{array}$ \\
\hline & $\begin{array}{l}\text { 16. Em 2015, o Protocolo de Nagóia (Nagoya) sobre o Acesso a Recursos Genéticos e a repartição Justa e } \\
\text { Equitativa de Benefícios Resultantes de sua utilização deve estar em vigor e operante, consistindo em } \\
\text { legislação nacional. }\end{array}$ \\
\hline \multirow{4}{*}{ 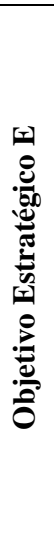 } & $\begin{array}{l}\text { 17. Em 2015, cada Parte deve desenvolver, adotar como instrumento de política, e iniciar a implementação de } \\
\text { um plano de ação e uma estratégica de biodiversidade nacional, participativa e atualizada. }\end{array}$ \\
\hline & $\begin{array}{l}\text { 18. Em } 2020 \text {, o conhecimento tradicional, inovações e práticas de indígenas e comunidades locais relevantes } \\
\text { para a conservação e uso sustentável da biodiversidade, e seu uso costumeiro de recursos biológicos, devem } \\
\text { estar respeitados, sujeitos à legislação nacional e obrigações internacionais relevantes, e totalmente integrados } \\
\text { e refletidos na implementação da Convenção com a participação total e efetiva de comunidades indígenas e } \\
\text { locais, em todos os níveis relevantes. }\end{array}$ \\
\hline & $\begin{array}{l}\text { 19. Em } 2020 \text {, o conhecimento, a base de ciência e tecnologias relacionadas à biodiversidade, seus valores, } \\
\text { funcionamento, situação e tendências, e as consequências de sua perda, devem estar melhorados, amplamente } \\
\text { compartilhados, transferidos e aplicados. }\end{array}$ \\
\hline & $\begin{array}{l}\text { 20. Em 2020, no máximo, a mobilização dos recursos financeiros para implementação eficaz do Plano } \\
\text { Estratégico para Biodiversidade 2011-2020 de todas as fontes, e de acordo com o processo consolidado e } \\
\text { acordado na Estratégia para Mobilização de Recursos, deverá estar substancialmente superior aos níveis atuais. } \\
\text { Esta meta está sujeita a alterações decorrentes das avaliações da necessidade de recursos que serão elaboradas } \\
\text { e relatadas pelas Partes. }\end{array}$ \\
\hline
\end{tabular}

Fonte: São Paulo (2013)

\subsection{SELEÇÃO E AVALIAÇÃO DOS CRITÉRIOS}

Tendo como base o cenário municipal, foram selecionadas para análise as metas aplicáveis ao contexto do Plano Diretor de 2005 (PD) e do Plano Diretor Estratégico (PDE). Com base na descrição de cada componente das Metas Aichi, ocorreram buscas sobre o conteúdo necessário para o atendimento das metas nos documentos oficiais disponibilizados digitalmente pela Prefeitura Municipal de São Carlos.

Posteriormente, tendo como base a classificação realizada por Fischer (2010, p.63), notas foram atribuídas para cada meta perante o atendimento das premissas estabelecidas pelo PD e PDE ao serem comparados com as Metas Aichi, bem como a qualidade das informações presentes nos documentos disponíveis nos endereços eletrônicos oficiais. Esta metodologia de atribuição de notas foi utilizada, 
seguindo a premissa de avaliação de acordo com as propostas da Avaliação Ambiental Estratégica (AAE) para avaliação de planos. Sendo um instrumento de apoio à tomada de decisão que visa a promoção do Desenvolvimento Sustentável. As notas foram atribuídas conforme:

- Grau A: O trabalho foi bem realizado e sem omissões importantes;

- Grau B: Foi realizado de forma satisfatória e completa, com apenas pequenas omissões/ inadequações;

- Grau C: Foi considerado como apenas satisfatória, apesar de algumas omissões ou insuficiências;

- Grau D: Indica que as partes estão bem, mas, em geral, são insatisfatórios devido a omissões ou insuficiências;

- Grau E: Não é satisfatório, revelando omissões ou insuficiências significativas;

- Grau F: É muito insatisfatória com tarefas importantes mal elaboradas.

- Grau G: A tarefa não atende a nada.

\section{RESULTADOS E DISCUSSÃO}

Foram analisadas as metas 2, 3, 4, 5, 7, 8, 11, 12, 14, 15 para os dois planos. As demais metas não foram avaliadas pois abordam temas que não se correlacionam com as características presentes no município de São Carlos ou com as competências legislativas e executivas municipais.

No PD pode-se observar ausência de informações essenciais necessárias à contemplação da meta 02. Apesar da erradicação da pobreza ser considerada uns dos princípios fundamentais, não há nenhum indício da integração entre erradicação da pobreza e biodiversidade. Dessa forma, foi atribuída a nota $F$ (Figura 2): “Art. $2^{\circ}$ I - Promoção da justiça social, da erradicação da pobreza, da erradicação da exclusão social e redução das desigualdades sociais e regionais".

Em relação ao PDE no que se refere à meta 2, também não existe uma integração explícita entre a conservação da biodiversidade e redução da pobreza. São elencadas áreas que devem ser consideradas no processo de planejamento e o estabelecimento de metas como a erradicação da pobreza e preservação do ambiente natural. Entretanto, não ocorre o devido detalhamento das informações em função de algumas omissões no PDE, desse modo a nota C foi atribuída: "Art. $2^{\circ}$ I - A Função Social da Cidade compreende o atendimento das necessidades dos cidadãos quanto à qualidade de vida, à justiça social".

Com relação à meta 3, o PD não considera como foco principal o incentivo à preservação da biodiversidade. A seção II elenca, porém, não discute que os Estudos de Impacto Ambiental (EIA), Relatório de Impacto Ambiental (RIMA), Estudo de Impacto de Vizinhança (EIV) e o Relatório de Impacto de Vizinhança (RIVI) podem contribuir para a preservação da biodiversidade.

O PDE elenca os incentivos fiscais como instrumento, porém não deixa explícito como esses incentivos agem e quais são os seus objetivos. Outros componentes relativos as metas são abordados durante algumas passagens no PDE tais como redução de impactos e proteção da biodiversidade de forma indireta. Visto que a meta 3 não foi abordada explicitamente, atribuiu-se a nota $E$ para o PD em função das omissões de dados e nota D para o PDE, visto sua maior complementariedade em relação ao o outro plano:

Art. $3^{\circ} \mathrm{X}$ - Proteger as áreas de preservação permanente, as unidades de conservação, as áreas de proteção dos mananciais e a biodiversidade.

Seção I - II - Proteger a biodiversidade, áreas com vegetação significativa ou reflorestamento de espécies nativas. 


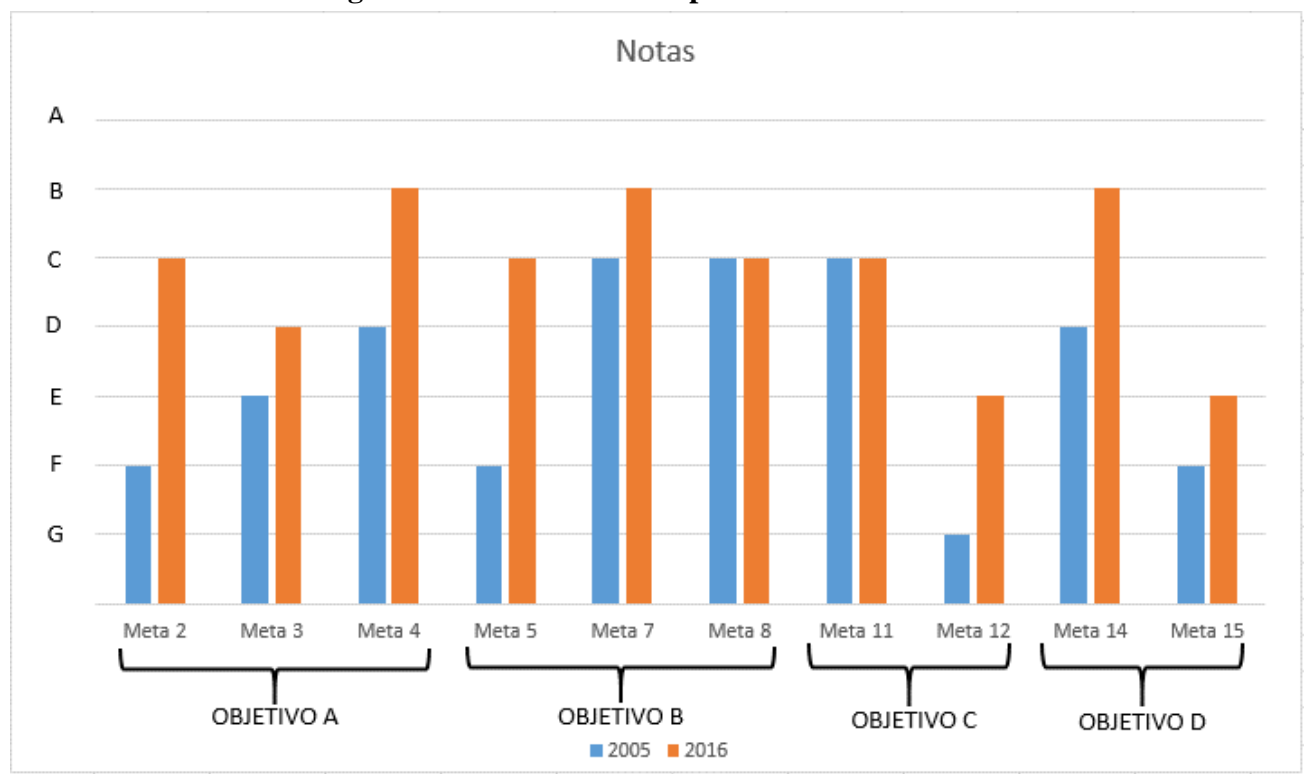

Fonte: Os autores

No que se refere à meta 4, o PD aborda o consumo dos recursos naturais e produção sustentável com incentivo a agricultura familiar, porém não estabelece limites ecológicos claros à exploração, o que incidiu na atribuição da nota D: "Art. $19^{\circ}$ VII - A constituição do mapeamento agroambiental do município para que o uso rural seja compatibilizado com os recursos naturais".

Por sua vez, o PDE menciona os impactos relacionados com o uso dos recursos naturais, consumo e produção sustentável, medidas que visam a proteção e a conservação ambiental mediante o direcionamento do uso e ocupação do solo para a promoção da sustentabilidade. Nota-se que o trabalho foi realizado de forma satisfatória e frente a existência de pequenas omissões, a nota B foi atribuída:

Art. $209^{\circ}$ VII - Assegurar a utilização adequada e sustentável dos recursos ambientais, culturais, urbanos e humanos.

Art. $3^{\circ} \mathrm{XV}$ - Viabilizar condições para que as propriedades rurais cumpram sua função social, tendo como base para a produção de alimentos, o desenvolvimento sustentável.

Tratando-se da meta 5, o PD aborda a questão do estabelecimento de áreas especialmente protegidas, mas carece de informações relacionadas com as medidas a serem adotadas para garantir a preservação efetiva dessas áreas e das metas para cumprimento dos objetivos propostos. Dessa maneira, foi atribuída nota F:

Art. $19^{\circ}$ IV - Designar as unidades de conservação ambiental e outras áreas protegidas por Lei, discriminando as de preservação permanentes ou temporárias, nas encostas, nas bordas de tabuleiros ou chapadas ou, ainda, nas áreas de drenagem das captações utilizadas ou reservadas para fins de abastecimento de água potável e estabelecendo suas condições de utilização.

No PDE, os fatores relacionados com a redução da taxa de perdas de habitats naturais encontramse implícitos no documento, contudo, medidas não são apontadas para que ocorra reduções na taxa de perda dos habitats naturais, incidindo assim no atendimento apenas satisfatório da meta com omissões, atribuindo-se a nota $\mathrm{C}$ : 
Art. $75^{\circ}$ - As Áreas Especiais de Controle e Recuperação Ambientais são porções do território que passaram por distintas intervenções antrópicas que causaram ou apresentam potencial de causar danos ambientais, e que necessitam de medidas específicas de controle e recuperação ambientais para que voltem a apresentar condições próximas das anteriores às intervenções, com objetivo de que as mesmas tenham a possibilidade de se transformar em áreas de preservação ambiental ou destinadas a parques e equipamentos públicos de uso coletivo, ou usos privados adequados após recuperação consolidada.

Com relação à meta 7, o PD aborda o estabelecimento de uma Zona de Produção de Agricultura Familiar, assim como o incentivo a essa modalidade de cultivo, além de mencionar a compatibilização do uso do solo entre agricultura e meio ambiente e a oferta de alternativas ao modelo de monocultura extensiva. Entretanto, diante da falta informações a respeito do processo de desenvolvimento de implantação dessas alternativas, atribuiu-se a nota C:

Art. $23^{\circ}$ - A Macrozona de Uso Multifuncional Rural é composta por áreas de uso agrícola, extrativista ou pecuário, com áreas significativas de vegetação natural, condições de permeabilidade próximas aos índices naturais, por áreas de preservação ambiental formadas por reservas florestais, parques e reservas biológicas, bem como por áreas de usos não agrícolas, como chácaras de recreio, lazer, turismo, fazendas históricas, indústrias e sedes de distritos.

Porções do território destinadas à agricultura mediante a conservação da biodiversidade e gerenciamento sustentável aparecem no PDE. O documento também aponta a necessidade de incentivos para a agricultura familiar, o emprego de práticas agroecológicas e agroflorestais com vista à sustentabilidade em toda a zona multifuncional de São Carlos. Frente ao atendimento satisfatório do item e pequenas omissões existentes no conteúdo, atribuiu-se a nota B: "Art. $113^{\circ}$ - Áreas de Interesse da Agricultura Familiar e Camponesa são áreas onde se localizam pequenas e médias propriedades rurais baseadas na agricultura familiar ou camponesa, bem como assentamentos rurais, com tradições culturais e estruturas produtivas diversificadas".

Por sua vez, a meta 8 que se refere à poluição é contemplada de forma parcial no PD, bem como também no PDE. O combate à poluição é estabelecido como um objetivo, várias formas de poluição são elencadas (sonora, luminosa) e o Estudo de Impacto de Vizinhança é mencionado, porém nada consta sobre a poluição difusa, relacionada com os nutrientes e sua relação com a biodiversidade. Em ambos os casos, a nota $\mathrm{C}$ foi atribuída, como observado nos dois planos: "As atividades serão classificadas em Incômodas ou em não incômodas com base nos parâmetros de incomodidade".

A meta 11 traz a necessidade da criação de espaços especialmente protegidos para a biodiversidade e manutenção dos serviços ecossistêmicos, apesar de omissões de informações quantitativas a respeito das dimensões de áreas, o PD apresenta a Lei das Áreas de Proteção e Recuperação de Mananciais como dispositivo complementar, além de inserir a necessidade da avaliação de impacto nas áreas de mananciais e incluir tais localidades nas Áreas Especiais de Interesse Ambiental. O PDE ressalta a necessidade da criação de áreas especialmente protegidas (Unidades de Conservação), porém não mencionada a quantidade de áreas que serão criadas. Diante do atendimento apenas satisfatório da meta e a presença de omissões, em ambos os planos a nota $\mathrm{C}$ foi atribuída, como observado nos dois planos:

Designar as unidades de conservação ambiental e outras áreas protegidas por Lei, discriminando as de preservação permanentes ou temporárias, nas encostas, nas bordas de tabuleiros ou chapadas ou, ainda, nas áreas de drenagem das captações utilizadas ou reservadas para fins de abastecimento de água potável e estabelecendo suas condições de utilização.

Sobre os aspectos relacionados com a extinção de espécies tratados na meta 12, não é apresentada no PD nenhuma informação relacionada à proteção de espécies ameaçadas de extinção, sendo assim, 
atribuiu-se a nota G. O PDE trata sobre o assunto de maneira implícita, visto que aponta a necessidade de se proteger as espécies existentes. Frente ao atendimento não satisfatório da meta devido à presença de omissões significativas e inadequações dos dados, a nota $\mathrm{E}$ foi atribuída.

Se tratando da meta 14, o PD menciona a necessidade de preservação e recuperação de Áreas de Mananciais e Áreas Especiais de Interesse Ambiental, mas não é estabelecida uma relação com as comunidades em situação de vulnerabilidade social. Dessa maneira, foi atribuída nota D:

Art. $56^{\circ}$ - As Áreas de Especiais Interesses compreendem as porções do território que exigem tratamento especial por destacar determinadas especificidades, cumprindo funções especiais no planejamento e no ordenamento do território, complementando o zoneamento por meio de normas especiais de parcelamento, uso e ocupação do solo.

Já o PDE aborda a questão do fornecimento de serviços ambientais, enquadra os mananciais em uma categoria especial de proteção e estabelece medidas para sua preservação. No PDE é mencionada a necessidade de recuperar áreas de Preservação Permanente, observase a ausência de especificações para a restauração das áreas de mananciais e não consideração das comunidades vulneráveis. Apresar da existência de algumas omissões, a meta foi considerada satisfatória e a nota B foi atribuída:

Art. $2^{\circ} \mathrm{III}$ - Preservação dos recursos necessários à vida urbana e rural, tais como os mananciais, os corpos d'água, as áreas arborizadas e as reservas florestais.

Art. $3^{\circ} \mathrm{XV}$ - Proteger e recuperar as áreas de mananciais responsáveis pelo abastecimento de água no Município.

Por fim, apesar da abordagem das questões relativas à preservação e conservação das áreas no $\mathrm{PD}$, em nenhum momento é citada a prática de estoques de carbono, ou combate à desertificação presentes na meta 15. Atribui-se essa ausência de informações ao período em que o Plano foi elaborado, ou seja, tais objetos ainda não eram foco de discussões. Dessa maneira, foi atribuída nota $\mathrm{F}$, como observado nos princípios fundamentais: "Art. $2^{\circ}$ - IX - "Preservação e recuperação do meio ambiente natural".

O PDE aborda de forma indireta a necessidade de se recuperar áreas degradadas, Áreas de Preservação Permanente, entretanto, nada consta sobre aspectos relacionados com resiliência, estoques de carbono e o total de áreas a serem recuperadas. A nota $\mathrm{E}$ foi atribuída, dado o atendimento satisfatório da meta 15 e a existência de omissões significativas, como já observado no Art. $2^{\circ}$ seção III e Art. $3^{\circ}$ seção XV.

Como observado em São Carlos, ao considerarmos também os objetivos em termos globais, algumas avaliações das metas AICH demostraram que os esforços direcionados para a redução da perda de biodiversidade não surtiram efeito, onde a velocidade de extinção da diversidade biológica é a maior já evidenciada (BUTCHART et al. 2010, p.1165).

A Secretariat of the Convention on Biological Diversity (2014) constatou durante a análise do progresso do Plano Estratégico para a Biodiversidade (2011 - 2020) que os componentes das metas, as quais foram consideradas na avaliação do PD e PDE de São Carlos, encontram-se na direção do objetivo estabelecido, mas os esforços destinados são insuficientes e caso os esforços não aumentarem, não ocorrerá a efetivação das metas dentro do prazo estabelecido.

Apesar disso, alguns componentes não apresentaram progresso significativo por se afastaram do alvo estabelecido (eliminação ou reforma dos subsídios nocivos à biodiversidade, redução da perda de 
habitats em 50\% ou próximo de zero, extinção de espécie e conhecimento das espécies ameaçadas), ou até mesmo os resultados indicam pioras (redução da degradação e fragmentação, poluição ocasionada pelo excesso de nutrientes, resiliência dos ecossistemas e contribuição da biodiversidade para estoque de carbono) no cenário mundial.

Constata-se que o PDE contemplou os componentes constituintes das Metas de Aichi de modo mais satisfatório do que o PD, visto o menor número de deficiências significativas existentes nas informações, bem como um melhor detalhamento do plano. Ainda assim, em ambos os casos avaliados verifica-se que os componentes das Metas de Aichi não foram atendidos de forma completamente satisfatória em toda sua totalidade e em alguns momentos as informações mostraram-se distantes do alvo estabelecido por cada objetivo, resultados condizentes com os analisados pela Secretariat of the Convention on Biological Diversity em 2014.

\section{CONSIDERAÇÕES FINAIS}

As Metas de Aichi pertinentes ao PDE mostraram inadequações e/ou omissões, algumas foram contempladas de forma satisfatória e outras apresentaram deficiências, logo se enquadraram como insatisfatórias quanto a totalidade do conteúdo de cada meta. A partir de uma análise comparativa entre os Planos de 2005 e o atual, observa-se um significativo desenvolvimento, principalmente ligado às questões como preservação da biodiversidade e integração entre questões relativas as esferas sociais e ambientais.

Os resultados mostraram que o PDE que se encontra em processo de revisão necessita de alterações para inserir de modo integral no planejamento, as metas relativas ao Plano Estratégico da CDB para a Biodiversidade, conforme o compromisso assumido pelo governo brasileiro. Recomendase a revisão do plano em processo de revisão para que ocorra a inserção dos elementos deficientes das Metas de Aichi, para que assim ocorra a promoção da conservação da biodiversidade e um desenvolvimento sustentável no município de São Carlos.

\section{AGRADECIMENTOS}

A Fundação de Amparo à Pesquisa do Estado de São Paulo (FAPESP) Processo: 2015/19918-3 pelo apoio na realização do trabalho.

\section{REFERÊNCIAS}

BALMFORD, A.; BRUNER, A.; COOPER, P.; COSTANZA, R.; FARBER, S.; GREEN, R.E.; JENKINS, M.; JEFFERISS, P.; JESSAMY, V.; MADDEN, J.; MUNRO, K.; MYERS, N.; NAEEM, S.; PAAVOLA, J.; RAYMENT, M.; ROSENDO, S.; ROUGHGARDEN, J.; TRUMPER, K.;TURNER, R. K. Economic Reasons for Conserving Wild Nature. Science, n.297, p. 950-953, 2002.

BRAGA, R. Aspectos da Ordenação Territorial nas Leis Orgânicas Municipais do Estado de são Paulo. Dissertação (Mestrado em Geografia), 87 f. São Paulo, FFLCH - USP, 1993.

BRAGA, R. Política urbana e gestão ambiental: considerações sobre o plano diretor e o zoneamento urbano. In: CARVALHO, P. F.; BRAGA, R. Perspectivas de Gestão Ambiental em Cidades Médias. Rio Claro: LPM-UNESP, p. 95-109, 2001. 
BRASIL. Constituição da República Federativa do Brasil,1988. Brasília, DF: Senado Federal: Centro Gráfico. Disponível em: 〈http://www.planalto.gov.br/ccivil_03/constituicao/constituicao.htm〉. Acesso em: 25 de julho de 2017.

BUTCHART, S. H. M.; M. WLPOLE; B. COLLEN, A. VAN STRIEN, J. P. W. SCHARLEMANN, R.E.A. ALMOND, J.E.M. et al. Global Biodiversity: Indicators of Recent Declines. Science, n. 328, p. $1164-1168,2010$.

CDB. Convension On Biologic Diversity. Strategic Plan for Biodiversity 2011 - 2020, including Aichi Biodiversity Targets. Disponível em: <https://www.cbd.int/sp/ default.shtml〉. Acesso em: 15 de junho 2016.

CEPAGRI. Centro de Pesquisas Meteorológicas e Climáticas Aplicadas à Agricultura. Clima dos municípios paulistas. 2016. Disponível em: <www.cpa.unicamp.br/outrasinformacoes/clima_muni_224.html >. Acesso em: 31 de maio de 2016.

CNM. Confederação Nacional de Municípios. A importância do plano diretor para os municípios. Cartilha. $1^{a}$ edição, 2006, 32 p.

COMISSÃO NACIONAL DE BIODIVERSIDADE. Resolução CONABIO n. 06, de 03 de setembro de 2013. Dispõe sobre as Metas Nacionais de Biodiversidade para 2020. Ministério do Meio Ambiente, Brasília, 2013, 7 p.

DAVIES, Z. G.; EDMONDSON, J. L.; HEINEMEYER, A.; LEAKE, J. R.; GASTON, K. J. Mapping an Urban Ecosystem Service: Quantifying above-Ground Carbon Storage at a City-Wide Scale. Journal of Applied Ecology, v. 48, n. 5, p. 1125-1134, 2011.

FISCHER, T. B. Reviewing the quality of strategic environmental assessment reports for English spatial plan core strategies. Environmental Impact Assessment Review, 30, p. 62-69, 2010.

IBGE. Instituto de Geografia e Estatística. Divisão territorial brasileiro e limites territoriais: IBGE cidades - São Carlos. 2016. Disponível em:

<www.ibge.gov.br/cidadesat/painel/painel.php?codmun=351930\#>. Acesso em: 31 de maio de 2016.

IGC. Instituto Geográfico e Cartográfico. Região administrativa Central, 2016. Disponível em: <www.igc.sp.gov.br/>. Acesso em: 31 de maio de 2016.

MENDONÇA, T. A. Urbanização sob o capitalismo e seus problemas. Universidade Estadual Vale do Acaraú - UVA - Disciplina: Espaço Urbano, 2016,16p. Disponível em:

<http://www.tiberiogeo.com.br/texto/TextoUvaUrbanizacaoCapitalismoProblemas.pdf >. Acesso em: 30 de julho de 2016.

MMA. Ministério do Meio Ambiente. Convenção sobre Diversidade Biológica (CDB), 2016. Disponível em: <www.mma.gov.br/biodiversidade/convencao-da-diversidade-biologica>. Acesso em: 30 de julho de 2016.

REZENDE, D. A.; ULTRAMARI, C. Plano diretor e planejamento estratégico municipal: introdução teórico-conceitual. Revista de Administração Pública, v. 41, n. 2, p. 255-271, 2007.

SANTOS, J. E.; NOGUEIRA, F.; PIRES, J. S. R.; OBARA, A. T.; PIRES, A. M. Z. C. R. The value of the Ecological Station of Jatai's ecosystem services and natural capital. Revista Brasileira de Biologia, n.61, p.171-190, 2001. 
SÃO CARLOS. Prefeitura Municipal de São Carlos. Plano Diretor Municipal. Disponível em: <www.saocarlos.sp.gov.br/index.php/habitacao-morar/166049-plano-diretorestrategico.html>. Acesso em: 25 de abril de 2016.

SÃO PAULO. Plano de Ação de São Paulo - Plano Estratégico para a Biodiversidade 2011- 2020. Secretaria de Meio Ambiente, 2013, 65p.

SEADE. Fundação Sistema Estadual de Análise de dados. Perfis Municipais, 2016. Disponível em: <www.seade.gov.br/produtos/perfil/perfil.php>. Acesso em: 31 de maio de 2016.

\section{SECRETARIAT OF THE CONVENTION ON BIOLOGICAL DIVERSITY - SCBD. Global Biodiversity Outlook 4, Montreal, 2014, 155p.}

SOUZA, M. N. Degradação e recuperação ambiental e desenvolvimento sustentável, 2004. Tese (Doutorado em Ciência Florestal). 393f. Universidade Federal de Viçosa - MG, 2004.

TREVISAN, D. P. Análise das variáveis ambientais causadas pelas mudanças dos usos e cobertura da terra do município de São Carlos, São Paulo, Brasil. São Carlos, 2015. 80 f. Dissertação (Mestrado) - Universidade Federal de São Carlos, São Carlos, 2015.

VILLAÇA, F. Dilemas do plano diretor, 2010. Disponível em: <www.flaviovillaca.arq.br/pdf/cepam2.pdf>. Acesso em: 21 de junho de 2016. 